\title{
Environment of East Kazakhstan: state and main directions of optimization
}

\author{
Turgai Alimbaev ${ }^{1}$, Bibizhamal Omarova $^{2}$, Bibihadisha Abzhapparova ${ }^{3}$, Kulpash $_{\text {Ilyassova }}{ }^{3}$, \\ Kuralay Yermagambetova ${ }^{3}$, and Zhanna Mazhitova, ${ }^{2, *}$ \\ ${ }^{1}$ Buketov Karaganda State University, 28, Universitetskaya str., 100028, Karaganda, Republic of \\ Kazakhstan \\ ${ }^{2}$ Astana Medical University, 49a, Beybitshilik str., 010000, Nur Sultan, Republic of Kazakhstan \\ ${ }^{3}$ L. N. Gumilyov Eurasian National University, 2, Satpayev str., 010008, Nur Sultan, Republic of \\ Kazakhstan
}

\begin{abstract}
This article discusses issues related to optimizing the state of East Kazakhstan environment. It is emphasized that along with the industrial progress observed in recent years in the East Kazakhstan region in such sectors of the economy as machinery and metal working, heat and power, woodworking, timber, light and food industries, production of building materials, the level of environmental pollution has increased. The article gives examples of how the activities of the enterprises of metallurgical industry, heat power engineering and motor transport cause a real threat of the environmental crisis in the region. It is concluded that the solution of the environmental problem is possible through comprehensive measures, including the issues of increasing the efficiency of use and protection of water resources, reducing the chemical load on the soil, creating infrastructure for waste processing, improving the health and quality of life of the residents of the region. These measures together can contribute to overcoming the current environmental crisis of the East Kazakhstan region and radically improving the environment as well become the key to optimizing the region's environment. The methodological basis of the study is the principle of scientific objectivity, which allows analyzing the subject under study taking into account the realities of economic changes in the region.
\end{abstract}

\section{Introduction}

At the moment, one of the important factors for the successful development of the republic is the solution of environmental problems in different regions of Kazakhstan [1, 2]. One of such regions where the environmental safety problem is acute is the East Kazakhstan region (hereinafter EKR. - Authors), which is one of the industrially developed regions of the Republic of Kazakhstan. The presence of rich mineral deposits creates the conditions for economic growth in the region. The base industry is non-ferrous metallurgy, which accounts for about $60 \%$ of the industrial potential of the region. The region has significant reserves of mineral resources and its main wealth is polymetallic ores, which

\footnotetext{
*Corresponding author: mazhitova_69@mail.ru
} 
contain zinc, lead, copper, rare and precious metals. The main directions of the regional economy are also engineering and metalworking, heat and power, woodworking, timber, light and food industries, and the production of building materials. Coal deposits are located in the Semipalatinsk region and on the territory of the Zaysan region as well as the largest in the world Semipalatinsk nuclear test site was located there. There are significant reserves of gold, rare and rare earth metals, raw materials for the production of cement, glass slag, shale and zeolite deposits in the region. Non-ferrous metallurgy is developed on the basis of polymetal deposits of the Ore Altai. On the Ertis River there are UstKamenogorsk, Ulba and Bukhtarma hydropower plants. Natural wealth has become a determining factor in the economic development of Irtysh. The presence of non-ferrous metal deposits in the bowels of East Kazakhstan contributed to the development of the mining industry. On the basis of lead-zinc, polymetallic deposits, large mining and metallurgical enterprises operate in Ridder, Altai, Ust-Kamenogorsk, in the upper UbaShemonaikha, Zmeinogorsk and Kursum-Karshig. In the republican volume, over $30 \%$ of the extraction of non-ferrous metal ores is accounted for by enterprises of the East Kazakhstan region. About $45 \%$ of lead, almost $50 \%$ of zinc and $90 \%$ of rare metals of the republic are produced here. Thus, a significant part of the non-ferrous metallurgy enterprises of the republic was concentrated in East Kazakhstan, which has the most negative impact on the natural environment and public health. In this industry, technological processes involve significant amounts of land. The processes of obtaining non-ferrous metals are water-intensive accompanied by tangible emissions of pollutants into the atmosphere. The development of the productive forces of East Kazakhstan fully corresponded to the general trends of the country's economic development, being realized for a long time without taking into account the environmental characteristics of the region with an increase in deformations of sectoral proportions and socio-economic structure. All this led to a serious aggravation of the ecological situation not only in industrial centers, but also in the entire region as a whole.

\section{Discussion of the results}

\subsection{Statement of the problem}

Environmental pollution has affected the quality of food. The incidence and mortality of the population increased, especially in childhood. The industrial structure in East Kazakhstan has become the main reason for a wide range of environmental problems, the nature of which, in turn, was largely determined by the activities of a specific complex of industries, their degree of impact on the quality of atmospheric air, surface and underground waters, the state of soils, forests and other natural spheres. In this regard the inclusion of almost all industrial centers of East Kazakhstan in the category of districts with a disturbing and difficult environmental situation at the beginning of the $21^{\text {st }}$ century was illustrative. At the same time, the most important components that determine the current general environmental situation are the real state of the air and water basins, and the consumption of water resources.

\subsection{Ecological crisis in the atmosphere and its impact on society}

Due to the rapid development of industry and transport, pollution of air, which is a vital part of the human environment, has turned into one of the most difficult environmental problems of our time in recent decades. Despite the fact that Kazakhstan is not the main supplier of air pollutants in comparison with industrialized countries, according to the 
Ministry of Environment and Water Resources of the Republic of Kazakhstan at the beginning of the $21^{\text {st }}$ century the level of air pollution in cities remained quite high even by international standards. Statistics of the last decade of the twentieth century showed the reduction of emissions of harmful substances into the atmosphere from stationary sources. Nevertheless, the degree of anthropogenic pressure on the natural environment of the East Kazakhstan region remained quite high. The level of air pollution in the cities of UstKamenogorsk and Ridder for a number of ingredients was 1.1-2.5 times higher than the average for Kazakhstan. Non-ferrous metallurgy enterprises made the largest contribution to overall indicators $-5 \%$. In accordance with this fact, three cities with the most intense pollution of the air basin stood out in the region, i.e., Ridder where zinc, lead, and precious metals were concentrated; Altai as a city where silver, gold, lead, zinc are mined; UstKamenogorsk is the center of non-ferrous metallurgy in Kazakhstan [3].

Air emissions still remain high and amount to 660 thousand tons per year or an average of $550 \mathrm{~kg}$ per inhabitant of the region. Air pollution in the East Kazakhstan region is caused by emissions from mining enterprises, heat power engineering, non-ferrous metallurgy and related industries - energy, engineering, construction industry and others. According to the Committee on Statistics, the number of stationary polluting sources decreased in 2018 and amounted to 20,790 units, which is 1,563 less sources than in 2017 (22,353 units). Among them, the main pollutants are Kazzinc LLP, UK TMK JSC, UMP JSC, Vostoktsvetmet LLP, Sekisovskoye RSE LLP, Altai Ken Baiytu LLP, Saykan LLP, in the energy sector LLP NPP UKTPP, Sogrinskaya CHP LLP, Ridder CHP JSC, Teplokommunenergo Public Utility, mechanical engineering - Vostokmashzavod LLP, construction industry Bukhtarminskaya Cement Company LLP, Semey Cement Plant LLP, public utilities Oskemen-Vodokanal and Semey-Vodokanal. However, in 2018, the total volume of atmospheric emissions from stationary sources, according to the Committee on Statistics, increased slightly compared to 2017 (129.3 thousand tons) and amounted to 130.7 thousand tons. The main pollutants in the East Kazakhstan region are carbon monoxide, sulfur dioxide, nitrogen dioxide and solid particles. Emission volumes of the main pollutants are given in table 1 [4].

Table 1. The volume of emissions of pollutants into the atmosphere from stationary sources of the East Kazakhstan Region.

\begin{tabular}{|c|c|c|}
\hline \multirow{2}{*}{ Name of pollutants } & \multicolumn{2}{|c|}{ Emission volumes (thousand tons) } \\
\cline { 2 - 3 } & $\mathbf{2 0 1 7}$ & $\mathbf{2 0 1 8}$ \\
\hline Sulfur Anhydride & 42.3 & 41.6 \\
\hline Nitrogen dioxide & 16.9 & 17.0 \\
\hline Solid particles & 28.4 & 30.2 \\
\hline Carbon monoxide & 33.7 & 33.6 \\
\hline
\end{tabular}

In addition to emissions from stationary sources, emissions from motor vehicles make a significant contribution to air pollution, which accounts for $30 \%$ of the total emissions. The main reason for the high content of harmful substances in the exhaust gases of automobile transport is the low quality of transport fuels and the lack of filters for cleaning exhaust gases, as well as the deterioration of the technical condition of the rolling stock of motor transport establishment and the increase in car fleets in the city.

Observations of the state of atmospheric air in the East Kazakhstan region are carried out by the "Kazhydromet" RSE at 17 observation posts in the cities of Ust-Kamenogorsk (7 posts), Ridder (3 posts), Semey (4 posts), Altai (1 post) and the village of Glubokoy (2 posts). In Ust-Kamenogorsk (air pollution index (hereinafter API. - authors) = 9), Ridder $(\mathrm{API}=5)$ and Semey (API = 5), the level of air pollution did not change compared to 2017 characterized as "high" and "increased". In the village of Glubokoye the level of air pollution compared to 2017 has changed from "high" (API = 8) to "increased" (API = 5). In 
general, since the beginning of 2018, in the city of Ust-Kamenogorsk, 1,530 cases of high pollution (HP) and 64 extremely high pollution (EHP) were recorded by the Kazhydromet RSE.

Ust-Kamenogorsk is the city with the most unfavorable atmosphere, the share of which is more than $42 \%$ compared to other industrial cities of the region. According to the East Kazakhstan Hydrometeorological Center, since 1997 in the city of Ust-Kamenogorsk there has been an increase in API. In 1999, the average API was 17.6 units, in 2000 - 17.8; and in 2001, the average API was 12.8. By comparison, Shymkent takes the second place (API $=11.3)$, Ridder takes the third (API $=10.2)$ [5]. In general, the ecological state of the environment of Ust-Kamenogorsk is characterized as follows. In conditions of poor ventilation of the city (the average calm percentage is $48 \%$ ), with a large number of vehicles and stationary sources, the relevance of air pollution in Ust-Kamenogorsk is not in doubt. The city has 169 enterprises with over 3 thousand stationary sources causing environmental damage to both biocenoses and the city population. According to the division of enterprises into hazard categories, depending on the mass and composition of pollutants emitted into the atmosphere, 6 city enterprises are assigned to the first category. These are the Ust-Kamenogorsk PE Kazzinc OJSC, which gives $74 \%$ of emissions, UstKamenogorsk CHP, Sogrinsk CHP, Ust-Kamenogorsk Thermal Networks, Altai Power NPP, which account for about 23\%, Experiment Lead Plant CJSC and UMP OJSC.

The share of small enterprises in air pollution is small, but together they also contribute to the pollution of the city.

Out of 170 names of polluted components emitted, about $20 \%$ belong to the first and second hazard class, i.e., these are selenium, lead, cadmium, arsenic, hydrogen fluoride, chlorine, etc. The condition of Ust-Kamenogorsk air basin in terms of sulfur dioxide content is especially unfavorable. The average annual excess of maximum permissible concentrations (MPC) in the city was: dust - 2.0 MPC, sulfur dioxide - 2.4 MPC, nitrogen dioxide - 3.3 MPC, phenol - 2.7 MPC, inorganic compounds of arsenic - 1, 0 MPC, carbon monoxide and chlorine - 0.7 MPC. The maximum single concentrations were: dust - 5.2 MPC, phenol - 4.9 MPC, nitrogen dioxide - 4.7 MPC, carbon monoxide - 2.4 MPC, sulfur dioxide - 1.1 MPC, chlorine - 1.0 MPC, formaldehyde - 0.9 MAC. High concentrations of pollutants exceeding MPC by five or more times are observed especially during adverse weather conditions (AWC). During the $1^{\text {st }}$ quarter of 2002, high atmospheric air pollution up to 6.7 average daily MPC was observed in the city as a whole according to the content of suspended particles during the AWC periods of 2 degrees. On the same days in the area of Zashchita station phenol content reached 5.7 daily average MPC. Compared to last year, the average dust content increased by $0.7 \mathrm{MPC}$, nitrogen dioxide and formaldehyde - by 0.6 MPC, arsenic - by $0.3 \mathrm{MPC}$; the phenol content decreased - by $0.3 \mathrm{MAC}$, sulfur dioxide by 0.4 MAC. The content of carbon monoxide and chlorine has not changed. The highest level of pollution with all impurities is observed in the area of the pollution observation post-1, for example, during the first decade of February, the lead content exceeded the sanitary norm by 2.8 times. Also, an excess of 1.2 times of lead MPC was observed during the $2^{\text {nd }}$ decade of February in the area of the pollution observation post-5 [6].

Currently, the state of atmospheric air in the city of Ust-Kamenogorsk is being monitored, carried out at 5 posts of observation on the content of dust, sulfur dioxide, nitrogen dioxide in the air; at 4 posts - phenol and formaldehyde observation; at 3 posts carbon monoxide observation; at 2 posts - chlorine, heavy metals, arsenic and lead observation. The content of other acutely toxic components such as beryllium, hydrogen fluoride is not controlled at all. Monitoring emissions from stationary sources is carried out as part of industrial monitoring by enterprises. On days with adverse meteorological conditions, a mobile post for air sampling is carried out in ecologically disadvantaged areas of the city in which there are no stationary posts. Based on this, Ust-Kamenogorsk for 
many years has been characterized by the highest level of air pollution among the regional centers of the Republic of Kazakhstan, despite the fact that in all enterprises of the city various activities and measures are developed within the framework of budget projects, the implementation of which requires a significant amount of funds.

This state of atmospheric air in the city of Ust-Kamenogorsk adversely affects the health of the population. The incidence of the upper respiratory tract, digestive system, endocrine system, circulatory system and respiratory system is increasing. In recent years, there has been a growing trend in the number of cancers, leukemia, tumors and other lifethreatening diseases. The situation is aggravated by the fact that many of the substances present in atmospheric air have so-called summation effect, when the negative effect on the human body is enhanced by the joint presence in the air of such substances as sulfur dioxide and hydrogen fluoride, sulfur dioxide and nitrogen dioxide, and carbon monoxide, etc.

\subsection{Ecology of water resources}

The territory of the region is rich in water resources represented by more than 800 rivers with a total length of over 10 thousand $\mathrm{km}$. The main waterway of the East Kazakhstan region is the Ertis River with tributaries - the mountain rivers Ulbi, Uba, Karakaba, Kaljir, Kurchum, Narym, Buktyrma and others. The water resources of the Yertis River and its tributaries are used for the needs of industry, housing and communal services, fisheries and agriculture: regular irrigation, the filling of estuaries and hayfields, agricultural water supply, pasture irrigation. The river's water resources are also used to generate hydropower and shipping needs. In order to maintain the Ertis River and preserve the biological productivity of the ecological habitat of the flora and fauna of the river floodplain, environmental protection measures are carried out annually through the Shulba reservoir. On the territory of the region there are large lakes, i.e., Zaysan, Markakol, Alakol, Sasykkol, as well as a large number of small lakes and reservoirs, among which the largest is Bukhtarminskoye (Buktyrma). In 2018, discharges of pollutants in the region amounted to 145002.99 thousand $\mathrm{m}^{3}$ [7].

Observations of surface water pollution in the territory of the East Kazakhstan region were carried out at 13 water bodies by the "Kazhydromet" RSE (the Rivers Kara Ertis, Ertis, Breksa, Tikhaya, Ulbi, Glubochanka, Krasnoyarka, Oba, Buktyrma, Emel, Ayagoz, Lake Markakol, reservoirs Buktyrma and Ust-Kamenogorskoe). The water quality in the examined water bodies is classified as follows: "high pollution level" (HPL) water - Kara Yertis, Yertis, Buktyrma, Oba, Ayagoz, Emel rivers, Markakol lake, Buktyrma and UstKamenogorsk reservoirs; water of "high pollution level" - the Breksa, Tikhaya, Ulbi, Glubochanka rivers; water of "extremely high level of pollution" (EHPL) is the Krasnoyarka River. Compared to 2017, the water quality in the Kara Yertis, Buktyrma, Yertis, Breksa, Tikhaya, Ulbi, Glubochanka, Oba, Emel, Ayagoz rivers, Buktyrma and UstKamenogorsk reservoirs has not changed significantly; in the Krasnoyarkf River and Markakol Lake it has worsened. According to the observations of the RSE "Kazhydromet" for 2018, 68 cases of HPL and 5 cases of EHPL were registered in the territory of the East Kazakhstan region: Breksa river (city of Ridder) - 12 cases of HPL, Tihaya river (city of Ridder) - 10 cases of HPL, Ulby river (Ridder and Ust-Kamenogorsk) - 19 cases of HPL and 3 cases of EHPL, Glubochanka river (Belousovka and Glubokoe villages) - 14 cases of HPL and 1 case of EHPL, Krasnoyarka river (Predgornoe village) - 13 cases of HPL and 1 case of EHPL [8]. 
Table 2. The number of cases of HPL and EHPL in the region for 2017-2018 [9].

\begin{tabular}{|c|c|c|c|c|}
\hline \multirow{2}{*}{ Water body } & \multicolumn{2}{|c|}{ Cases of high pollution } & \multicolumn{2}{c|}{$\begin{array}{c}\text { Cases of extremely high } \\
\text { pollution }\end{array}$} \\
\cline { 2 - 5 } & $\mathbf{2 0 1 7}$ & $\mathbf{2 0 1 8}$ & $\mathbf{2 0 1 7}$ & $\mathbf{2 0 1 8}$ \\
\hline Breksa River & 12 & 12 & - & - \\
\hline Tihaya River & 9 & 10 & - & - \\
\hline Ulbi River & 20 & 19 & - & 3 \\
\hline Glubochanka River & 26 & 14 & - & 1 \\
\hline Krasnoyarka river & 11 & 13 & 1 & 1 \\
\hline
\end{tabular}

The main causes of HPL and EHPL of water in the rivers of the East Kazakhstan region are the high technogenic load from mining enterprises and historical pollution (rock dumps, tailing ponds). The number of cases of HPL since 2017 in the Breksa, Tikhaya, Ulbi and Krasnoyarka rivers has changed by one or two units, in the Glubochanka River their number has significantly decreased - from 26 to 14 . The Krasnoyarka, Glubochanka, Ulbi rivers continue to be the most polluted by chemical indicators. A high-water pollution index of these rivers has been maintained over the past few years. The main pollutants are zinc, manganese, copper, cadmium, iron. The water quality characterization in these rivers corresponds to the "high" and "extremely high" pollution levels. The pollution of the Breksa, Tikhaya, and Ulbi rivers is caused by historical pollution from waste rock dumps, which are currently in state ownership, as well as discharges of Kazzinc LLP. The Krasnoyarka, Glubochanka rivers (near the Tishinsky mine, city of Ridder) are influenced by the existing enterprises of the mining complex - Vostoktsvetmet LLP. The main source of river pollution is the mine water of the Irtysh mine. Drainage of the sludge storage of Irtysh mine and Berezovsky tailings dumps, the spilling from the state-owned Kapitalnaya mine flows into the Krasnoyarka River. The pollution of the Glubochanka River is mainly due to historical pollution of the dump. Between 2005 and 2018 the East Kazakhstan regional akimat issued 84 decisions on the establishment of water protection zones and strips, including in the cities Ust-Kamenogorsk, Semey, Zyryanovsk, Ridder, Shemonaikha, on the coast of the Bukhtarma, Ust-Kamenogorsk and Shulba reservoirs, Alakol lake, etc. The total length of the established water protection zones is $1874 \mathrm{~km}$, an area of $67861 \mathrm{ha}$. The total length of the established water protection strips is $2463 \mathrm{~km}$, an area of 14792 hectares. In order to provide drinking water and modernize the drinking water supply system of settlements in 2018, initiated earlier prospecting and exploration work of groundwater for 40 settlements of the region was completed and additional exploration of 4 underground water deposits (Taskeskenskoye, Kamyshinskoye, Targynskoye and Kuraylinskoye) was executed. Also, prospecting and exploration work on 17 rural settlements of the region and additional exploration of one underground water field began in 2018. In order to prevent and eliminate flood threats, the Roadmap "A set of measures to prevent and eliminate flood threats for 2017-2020" (hereinafter referred to as the Roadmap) and the Plan for the conservation, accumulation and distribution of flood waters and restoration of facilities for livestock watering on pastures (hereinafter referred to as the Plan) were developed and approved. The Road Map for the East Kazakhstan Region includes 80 events, including: for 2017 - 21 events in 10 districts of the region; for 2018 22 events in 7 districts of the region. The Plan for the East Kazakhstan Region includes 60 measures for the repair of existing water storage tanks owned by the municipality. In 2018 ongoing repair of 45 storage tanks was carried out at the expense of the regional budget funds [10]. 


\subsection{Ecology of land resources}

Soil samples were taken in the cities of Ust-Kamenogorsk, Ridder and Semey to determine the content of heavy metals in the spring and autumn periods of 2018 by Kazhydromet RSE. The observation results are shown in table 4 [11].

Table 3. Concentrations of metals exceeding MAC in soil samples taken in different areas of cities for spring and autumn, $\mathrm{mg} / \mathrm{m}^{3}$.

\begin{tabular}{|l|c|c|c|}
\hline \multirow{2}{*}{ City } & \multicolumn{3}{|c|}{ Heavy metals, mg / kg } \\
\cline { 2 - 4 } & Lead & Copper & Zinc \\
\hline & Spring period & \multicolumn{2}{c|}{} \\
\hline Ust-Kamenogorsk & $2.4-21.7$ & $1.3-6.5$ & $1.2-4.0$ \\
\hline Ridder & $3.4-16.4$ & $1.2-6.0$ & $1.1-4.5$ \\
\hline Semey & 1.1 & 1.1 & - \\
\hline & Autumn period & $1.4-5.2$ & $2.1-2.7$ \\
\hline Ust-Kamenogorsk & $3.7-9.9$ & $1.6-4.9$ & $1.0-2.3$ \\
\hline Ridder & $3.8-8.0$ & 1.1 & - \\
\hline Semey & 1.2 & \multicolumn{2}{|c|}{} \\
\hline
\end{tabular}

The Department of Ecology in the East Kazakhstan region is working on the registration and accounting of pollution sites. In general, in the East Kazakhstan region, 284 pollution sites were registered. The problem of the disposal of household and industrial waste is of particular importance for large cities in the region, because the process of collection, disposal and landfilling of waste in most settlements did not meet the necessary sanitary and hygienic requirements for decades. As a result, industrial centers turned into places of formation and accumulation of giant volume of industrial and household waste, causing a critical situation at the end of the twentieth century at the landfills of almost all major cities. A significant part of them was accumulated and burned in the territories of enterprises, fell into a landfill of household waste, as well as it was arbitrarily taken to the suburban area, turning them into a hotbed of potential danger. An acute problem is the disposal of municipal solid waste in East Kazakhstan. At the same time, it became obvious that the solution to the problem of industrial waste includes not only its reducing, improving the technology for the decontaminating and disposal of waste and ensuring environmental safety, but also in creating a legal framework, including the organization and monitoring of waste; improvement and expansion of economic sanctions for the formation and misuse of industrial waste; environmental hazard assessment of waste and its location; development of waste hazard class criteria; ensuring environmental safety in the transboundary movement of hazardous waste. The territory of the region, which possessed generally rich soil resources, also faced the phenomenon of qualitative depletion of land resources. In many areas, there has been land degradation and a decline in natural fertility. The most alarming of them is the deficit of humus, which is an organic substance of the soil, resulting from the decomposition of plant and animal residues.

An alarming situation has developed with land resources. Wasteful attitude to the use of land, pollution by pesticides, waterlogging of soil, disturbances that contribute to the development of water and wind erosion, lead to a decrease in fertility and a reduction in useful areas. The use of highly toxic pesticides in almost all farms of the region contributes to the accumulation of persistent pesticides in soils. Most of the farms in the region do not ensure their high-quality storage, they are often stored in the open air or in unsuitable premises as well as the construction of typical storage facilities is extremely slow. In addition, violation of design conditions, sanitary norms and rules for the operation of gas stations, car parks, and manure depots causes great harm to the earth. Work is underway slowly to increase the area of green spaces in cities and districts of the region. To date, a significant area of disturbed land in the region needs to be recultivated. A large half of such 
lands is registered in mining and heat power enterprises. Existing worked open pits are used for group dumps of mine and overburden, as sludge sumps of concentration plants, quarries are being filled up. However, recently, due to lack of funds, there has been a sharp decline in the implementation of recultivation work, both at the energy enterprises and at the nonferrous metallurgy enterprises. It should be noted that the Semipalatinsk nuclear test site had a negative impact on the state of land in the region, and in particular the former Abay, Beskaragai, Abralinsky and Zhanasemeysky regions of the East Kazakhstan region. In recent years, some measures have been taken by environmental authorities to improve the environmental situation in the region. To improve work efficiency, a unified comprehensive program "Protection of Nature and Public Health" was reformed, which became the basis for coordination of all environmental activities in the region. Within the framework of this program, 26.5 billion tenge was allocated in 2018, which is 1.8 tenge more than in 2017 [12, p. 399]. In order to create a unified system of environmental safety, a state environmental review has been toughened. The most stringent requirements are made when considering projects of joint ventures and foreign firms.

\subsection{Tasks and possible ways to optimize the environment of the region}

Modern regional environmental problems arisen as a result of these shortcomings require significant intensification of the entire environmental management system as a whole, especially the sphere of land and forest use, the use of mineral deposits. A complex combination of natural and anthropogenic impacts, among which industrial impact is the most significant and problematic, is the basis for forecasts regarding the further aggravation of environmental problems. In this regard, the following promising directions for optimizing the state of the environment of East Kazakhstan seem to be most important: 1 . Improving the measures to protect atmospheric air through the introduction of treatment facilities and plants. 2. Improving the efficiency of use and protection of water resources, including improving the condition of small rivers, reservoirs, monitoring the status of groundwater. 3. Solving the problems of rational use of land, including protection against wind and water erosion, flooding, waterlogging and salinization. 4. Reducing the chemical load on the soil. 5. Creation of infrastructure for waste processing; expansion of the network of nature reserves, national parks and conservation areas. 6. Strengthening the protection, reproduction and rational use of the plant and animal world. 7. Improving the health and quality of life of the population. The priority area of activity of state bodies in these conditions should be the active use of economic, legal and organizational methods of influencing the emerging economic system, its maximum greening in order to balance the development of heterogeneous processes: the country's economic development and creation of a favorable natural environment for human life and health. In economic terms, environmental problems should be solved at the expense of various sources: budget, extrabudgetary funds, funds from enterprises, etc. The most reasonable is to determine the optimal amount of funds to ensure the required state of environmental condition. A flexible combination of direct regulation of the natural resources quality of and the environment and economic mechanisms for environmental management is needed: the greening of technical and technological policies at industrial facilities, in road transport and municipal service; implementation of environmental monitoring systems, compilation of a data bank based on environmental passports of facilities and territories; greening land and urban policy. In technological terms, a consistent transition to international environmentally friendly standards of technological processes and manufactured products should become the priority areas of environmental policy at the beginning of the XXI century. In our opinion, it is necessary to develop and stimulate the implementation of low-waste, resource and energysaving technologies and processes. The results can be achieved through the advances of 
scientific and technological progress, the intensification of research and development, environmental investment projects. Particular attention should be paid to the greening of nature users' consciousness and the formation of appropriate public opinion, since the changes taking place in the world necessitate the formation of a holistic humanistic worldview in relation to nature, in which priority importance will attached to universal human values. In the regional aspect, an important component in solving the environmental security problem of East Kazakhstan should become practical measures for the efficient allocation of funds for environmental protection and rational nature management. At the same time, the specificity and variety of environmental and economic transformations require a differentiated approach to the development and implementation of an economic mechanism for nature management. This confirms the importance of developing long-term environmental programs as the main component of environmental management and environmental protection in long-term plans for socio-economic development at the republican, regional and local levels.

\section{Conclusion}

Currently, in East Kazakhstan, under the influence of industrial activity hundreds of chemical pollutants are simultaneously present in the atmospheric air in a complex interaction that enhances or neutralizes their influence. An analysis of the industrial development of East Kazakhstan in the context of environmental problems allows to highlight the typical causes in a regional dimension of the critical state of the environment developed at the beginning of the $21^{\text {st }}$ century. This is, firstly, a technocratic approach to solving environmental problems, aimed not at radical socio-economic transformations, but aimed at quantitative, superficial changes, which, in particular, only increase the depersonalization of ownership of natural resources. Secondly, there are the contradictions that arise on the basis of the mismatch of imperfect, uneconomical technologies and equipment with the requirements of rational environmental management, which can subsequently lead to international environmental crisis. Thirdly, there is the irresponsibility and lack of control of the relevant ministries, departments, regional and local governments, whose activities are often aimed not for the benefit, but to the detriment of the environment. And fourthly, there is the lack of sufficient economic interest and responsibility of enterprises and organizations in environmental protection, which is currently not integrated with their core business. Fifthly, there is a one-sided consumer approach for the sake of short-term economic interests, which leads to a lack of long-term strategic principle in environmental protection activities, and finally in the sixth, the low level of environmental awareness, education and public awareness, as well as the administrative, scientific and technical apparatus of the relevant authorities and institutions. A practical and comprehensive solution to the above problems, in our opinion, can bring Kazakhstani society closer to improving the current environmental situation. However, this is not only a question of time, but it requires rather enormous financial costs from the state.

\section{References}

1. T. Alimbaev, Zh. Mazhitova, B. Omarova, Zh. Nurkina, IOP Conference Series: Materials Science and Engineering 663, 1-5 (2019)

2. T. Alimbaev, Zh. Mazhitova, B. Omarova, B. Kamzaev, M. Atanakova, E3S Web of Conferences 157, 1-8 (2020)

3. The newsletter on the state of the environment of the Republic of Kazakhstan 01(243) (Nur-Sultan, 2020) 
4. Zh. Uzdenbaeva, Proceeding of Abishev's readings "Liquid at the interface, theory and practice" (2006)

5. A. Adryshev, Actual problems of environmental safety and ways to solve them in Kazakhstan (EKSTU, Ust-Kamenogorsk, 2008)

6. National report on the state of the environment and on the use of natural resources of the Republic of Kazakhstan for 2017 (Astana, 2018)

7. A. Adryshev, Materials of the Internet conference Dynamics of Research 2008 23, 54 (2008)

8. Zh. Uzdenbaeva, Bulletin of D. Serikbayev East Kazakhstan state technical university 1, 74 (2006)

9. National report on the state of the environment and on the use of natural resources of the Republic of Kazakhstan for 2018 (Astana, 2019) 